\title{
Vestibular Neuritis
}

\author{
${ }^{1}$ Department of Neurology, Chungnam National University Hospital, \\ Daejeon, Korea \\ 2 Biomedical Research Institute, Seoul National University Bundang \\ Hospital, Seongnam, Korea \\ ${ }^{3}$ Department of Neurology, Seoul National University College of \\ Medicine, Seoul National University Bundang Hospital, Seongnam, \\ Korea
}

Seong-Hae Jeong, $\mathrm{MD}^{1}$ Hyo-Jung Kim, $\mathrm{MSc}^{2} \quad$ ji-Soo Kim, MD, $\mathrm{PhD}^{3}$

Address for correspondence Ji-Soo Kim, MD, PhD, Department of Neurology, Seoul National University College of Medicine, Seoul National University Bundang Hospital, 300 Gumi-dong, Bundang-gu, Seongnam-si, Gyeonggi-do 463-707, Korea (e-mail: jisookim@snu.ac.kr).

Semin Neurol 2013;33:185-194.

\begin{abstract}
\section{Keywords}

- vestibular neuritis

- vertigo

- nystagmus

- head impulse test

- vestibular evoked myogenic potential

Vestibular neuritis is the most common cause of acute spontaneous vertigo. Vestibular neuritis is ascribed to acute unilateral loss of vestibular function, probably due to reactivation of herpes simplex virus in the vestibular ganglia. The diagnostic hallmarks of vestibular neuritis are spontaneous horizontal-torsional nystagmus beating away from the lesion side, abnormal head impulse test for the involved semicircular canals, ipsilesional caloric paresis, decreased responses of vestibular-evoked myogenic potentials during stimulation of the affected ear, and unsteadiness with a falling tendency toward the lesion side. Vestibular neuritis preferentially involves the superior vestibular labyrinth and its afferents. Accordingly, the function of the posterior semicircular canal and saccule, which constitute the inferior vestibular labyrinth, is mostly spared in vestibular neuritis. However, because the rare subtype of inferior vestibular neuritis lacks the typical features of vestibular neuritis, it may be misdiagnosed as a central vestibular disorder. Even in the patient with the typical pattern of spontaneous nystagmus observed in vestibular neuritis, brain imaging is indicated when the patient has unprecedented headache, negative head impulse test, severe unsteadiness, or no recovery within 1 to 2 days. Symptomatic medication is indicated only during the acute phase to relieve the vertigo and nausea/vomiting. Vestibular rehabilitation hastens the recovery. The efficacy of topical and systemic steroids requires further validation.
\end{abstract}

Vestibular neuritis refers to a disorder characterized by acute, isolated, spontaneous vertigo due to unilateral vestibular deafferentiation. ${ }^{1}$ Even though the clinical features had been described previously, it was Dix and Hallpike who first coined the term vestibular neuronitis in 1952 to distinguish it from Ménière's disease. ${ }^{2}$

Vestibular neuritis accounts for 3.2 to $9 \%$ of the patients visiting a dizziness center, ${ }^{3,4}$ and has an incidence of $\sim 3.5$ per 100,000 population. ${ }^{5}$ Characteristic symptoms of acute vestibular neuritis include vertigo, nausea/vomiting, oscillopsia, and unsteadiness. ${ }^{6}$ Patients with vestibular neuritis show spontaneous horizontal-torsional nystagmus beating away from the lesion side, abnormal head impulse test (HIT) for the involved semicircular canals, ipsilesional caloric paresis, decreased responses of vestibular-evoked myogenic potentials (VEMPs) during stimulation of the affected ear, and unsteadiness with a falling tendency toward the lesion side. ${ }^{7}$

The vestibular labyrinth may be subdivided into the superior and inferior divisions (-Fig. 1). The superior vestibular labyrinth comprises the anterior (AC) and horizontal semicircular canals (HC), the utricle, and their afferents. In contrast, the inferior vestibular labyrinth consists of the posterior semicircular canal (PC), the saccule, and their afferents. The head impulse test enables us to evaluate the function of each semicircular canal, ${ }^{8,9}$ and VEMPs that reflect the function of the utricle and saccule ${ }^{10,11}$ are now able to securely diagnose the three distinctive patterns of vestibular neuritis, the superior, inferior, and total (superior + inferior) types.
Issue Theme Neuro-Otology 2013; Guest Editor, Terry D. Fife, MD
Copyright @ 2013 by Thieme Medical Publishers, Inc., 333 Seventh Avenue, New York, NY 10001, USA. Tel: +1(212) 584-4662. 


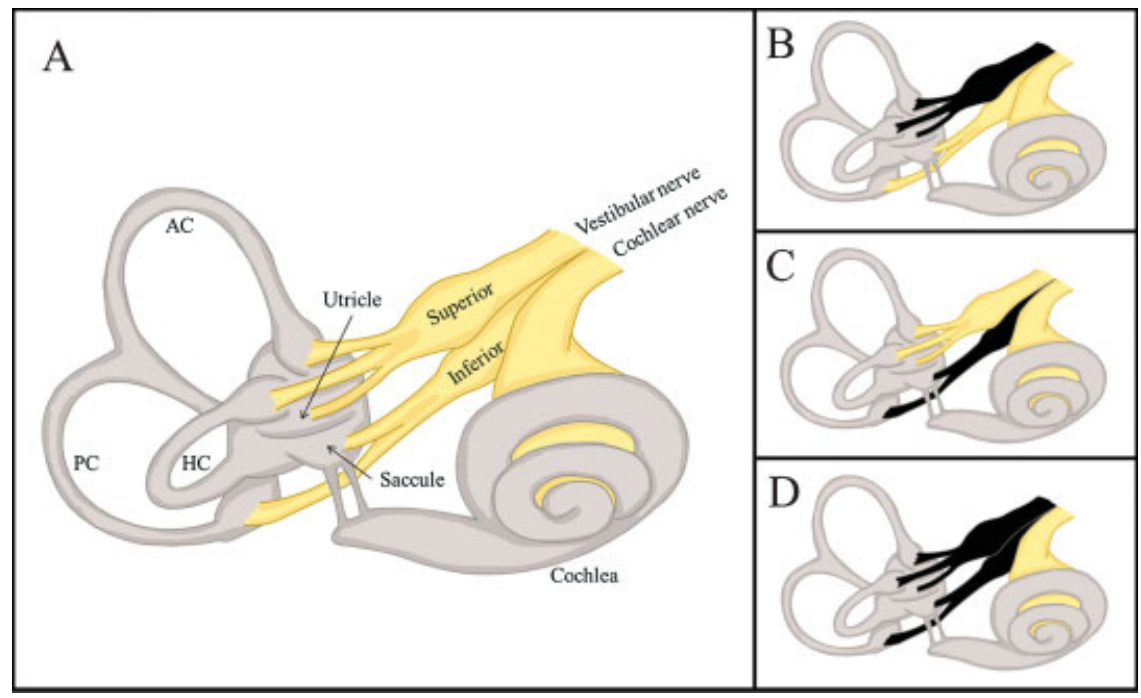

Fig. 1 Divisional configuration of the labyrinth and three distinctive types of vestibular neuritis. (A) The vestibular labyrinth may be subdivided into the superior and inferior divisions. The superior vestibular labyrinth comprises the anterior (AC) and horizontal semicircular canals (HC), the utricle, and their afferents. In contrast, the inferior vestibular labyrinth consists of the posterior semicircular canal (PC), the saccule, and their afferents. (B-D) According to the divisions involved, vestibular neuritis may be classified into distinctive types, the superior (B), inferior (C), and total (D).

Because vestibular neuritis preferentially affect the superior division, ${ }^{12}$ superior vestibular neuritis is most common (55$100 \%)$, followed by total (15-30\%) and inferior vestibular neuritis (3.7-15\%). ${ }^{12-18}$

Although vestibular neuritis itself is not life threatening, distinguishing vestibular neuritis from other debilitating disorders such as strokes is essential. ${ }^{19-22}$ The management of vestibular neuritis includes (1) symptomatic care for nausea/vomiting and vertigo, (2) etiological treatments, and (3) vestibular rehabilitation to improve central compensation. ${ }^{23}$

\section{Clinical Features}

Patients with vestibular neuritis mostly present with subacute or acute spontaneous vertigo with nausea/vomiting and unsteadiness. ${ }^{1}$ The symptoms may develop suddenly or evolve over several hours. Prodromal dizziness may be reported in $\sim 8.6$ to $24 \%$ of patients. ${ }^{24,25}$ Most (74\%) of the preceding episodes are described as nonvertiginous dizziness, often associated with a feeling of nausea or unsteadiness. The episodes may have abrupt or gradual onset, and may last a few minutes to days. ${ }^{24}$ Patients may have precedent or concurrent viral illnesses. $^{2,25}$

The vertigo in vestibular neuritis may gradually increase over several hours and reach a peak within the first day. ${ }^{1}$ Vertigo is usually described as rotational, and is markedly increased by head movements. Patients usually prefer to lie in bed with their eyes closed in a side position with the healthy ear down. Most patients suffer from severe nausea and vomiting. Severe vertigo improves markedly over 1 to 2 days.

Because stimulation of a single semicircular canal induces eye movements approximately in the plane of that canal, ${ }^{26}$ the patterns of spontaneous nystagmus in vestibular neuritis would depend on relative involvement of each semicircular canal. ${ }^{27}$ Accordingly, when all three canals are completely damaged, the nystagmus is mixed horizontal-torsional and the fast component of the spontaneous nystagmus is away from the affected side. However, the spontaneous nystagmus invariably accompanies a vertical component that is mostly upbeat because $\mathrm{AC}$ is more commonly affected than PC. As the nystagmus is markedly suppressed by visual fixation, proper observation of the nystagmus requires a removal of visual fixation using Frenzel glasses or infrared video goggles. The nystagmus increases during the gaze in the direction of the nystagmus and decreases when looking into the other direction (Alexander's law), but never changes directions. The nystagmus is mostly augmented by horizontal head shaking, vibratory stimuli on the mastoids or the brow, or hyperventilation. ${ }^{28,29}$

The spontaneous nystagmus gives rise to illusion of apparent movement of the environment (oscillopsia). Because the illusory visual perception of rotation is produced by the slow phase of the nystagmus in the opposite direction, rightbeating spontaneous nystagmus in left vestibular neuritis induces contraversive rightward (clockwise) rotation of the surroundings.

Patients tend to fall toward the affected side on standing with the feet together or on attempted walking. ${ }^{30}$ However, they should maintain sitting balance or stand unaided with the feet apart because the brain can still utilize the information for balance control via the visual and somatosensory systems.

\section{Etiology}

Although precedent or concurrent viral illnesses have been described in vestibular neuritis, ${ }^{2,25}$ evidence of systemic viral infection based on seroconversion remain unconvincing. ${ }^{25,31}$ The signs and symptoms confined to the vestibular nerve in most series do not support systemic viral infection either. Instead, increasing evidence suggests possible reactivation of 
latent type 1 herpes simplex virus (HSV-1) as a cause of vestibular neuritis, likewise in idiopathic facial paresis. ${ }^{32}$ HSV-1 DNA is detected on autopsy in about two of three human vestibular ganglia along with the expression of CD8positive $\mathrm{T}$ lymphocytes, cytokines, and chemokines. ${ }^{32}$ These findings indicate latent infection of the vestibular ganglia with HSV-1. ${ }^{33}$ Furthermore, inoculation of HSV induces vestibular dysfunction with infected vestibular ganglion cells in mice. ${ }^{34}$ Other possible mechanisms include autoimmune and microvascular ischemic insults to the vestibular labyrinth. ${ }^{4}$

Vestibular neuritis preferentially affects the superior division. ${ }^{12}$ In other words, vestibular neuritis is most likely partial with a predominant involvement of $\mathrm{AC}, \mathrm{HC}$, and the utricle. This may be ascribed to the anatomical differences between the superior and inferior vestibular nerves. ${ }^{35}$ The bony canal of the superior vestibular nerve is seven times longer than the singular nerve canal. ${ }^{35}$ Furthermore, the superior vestibular nerve and arteriole travel through a relatively narrower passage than the singular nerve and its vascular supply because there are more bony spicules occupying the superior vestibular compared with the inferior vestibular or singular channels. $^{35}$ Therefore, the superior nerve may be more susceptible to swelling or ischemic insults. Sparing of PC function in vestibular neuritis could also be explained by the relatively common double innervations of PC by two distinct nerves, which reach the posterior cupula through separate bony canals. ${ }^{36}$

\section{Evaluation}

During the acute phase, the spontaneous nystagmus may be seen even with visual fixation, but is better appreciated with removal of visual fixation. Nystagmus can be recorded and quantitatively analyzed using oculography. Three-dimensional video-oculography is commonly used, which can measure the direction and slow-phase velocity of spontaneous nystagmus. Nystagmus may be induced or modulated by various maneuvers such as head-shaking, vibration, or hyperventilation. ${ }^{28,29}$ Head-shaking nystagmus is mostly assessed by using a passive head-shaking maneuver. ${ }^{37}$ Vibration-induced nystagmus is recorded by applying a vibration stimulator to the forehead and both mastoids. ${ }^{28}$

A head impulse test can evaluate the function of each semicircular canal bedside. ${ }^{8} \mathrm{~A}$ bedside head impulse test is feasible, and the sensitivity is clinically acceptable. ${ }^{38}$ However, a bedside head impulse test may be negative, especially when the vestibular deficits are partial, ${ }^{39}$ or the corrective saccades are covert, i.e., the corrective saccades occur only during head impulse rather than after the head rotation. ${ }^{40}$ Furthermore, bedside head impulse tests in the planes of the vertical canals are more difficult to interpret than a horizontal head impulse test. ${ }^{18}$ In such cases, the quantitative head impulse test using video oculography or the magnetic search-coli technique would aid in detecting the deficits of the vestibulo-ocular reflex (VOR). ${ }^{16,41}$ A head impulse test has been suggested a predictor of symptom recovery in a previous study, ${ }^{42}$ in which $80 \%$ of patients with persistent dizziness had a positive head impulse test, whereas only $10 \%$ of patients without dizziness showed a positive head impulse test.

Unilateral caloric paresis has been the diagnostic hallmark of vestibular neuritis. However, caloric test can only evaluate the function of $\mathrm{HC}$ only in the lower frequency range $(\sim 0.003$ $\mathrm{Hz})^{1}{ }^{1}$ and would be normal in vestibular neuritis sparing $\mathrm{HC}$, likewise in inferior vestibular neuritis. ${ }^{18}$

Evaluation for the ocular tilt reaction (OTR) should include measurements of head tilt, skew deviation, and ocular torsion. ${ }^{4}$ Ocular torsion can be determined on fundus photos. ${ }^{4}$ The sensory manifestation of ocular torsion can be measured as a deviation of the subjective visual vertical (SVV). ${ }^{43-45}$ The SVV tilt can be determined bedside using a simple, self-made bucket, ${ }^{46}$ or be measured using a computerized program in the laboratory. 4,28

Even though the origins of cervical and ocular VEMPs remain controversial, ${ }^{47-52}$ cervical and ocular VEMPs appear to be valuable tools in evaluating the otolithic function in vestibular neuritis. ${ }^{50,53}$ Furthermore, the dissociated patterns of abnormalities in cervical and ocular VEMPs may provide important clues for determining the involved vestibular division in vestibular neuritis. ${ }^{15}$ In patients with vestibular neuritis and intact cervical VEMP evoked by airconducted sounds (ACS), the severity of ACS-induced ocular VEMP abnormality correlated with HC dysfunction on caloric or head impulse testing. ${ }^{15,54,55}$ In a recent study, patients with superior vestibular neuritis showed abnormal ocular VEMP and normal cervical VEMP in response to ACS. ${ }^{14}$ In contrast, patients with inferior vestibular neuritis have normal ocular VEMP and abnormal cervical VEMP induced by ACS. ${ }^{14,18}$ This study supports the use of ocular and cervical VEMPs in determining each subtype of vestibular neuritis.

The rotatory chair test has a limited diagnostic value in vestibular neuritis because whole-body rotation modulates the activities of both labyrinths simultaneously, which renders evaluation of unilateral vestibular dysfunction difficult. The horizontal VOR elicited by sinusoidal rotation is asymmetrical, and the VOR gain is decreased during velocity step rotation toward the affected ear, especially during the acute phase. ${ }^{56}$ In contrast, the VOR gain during velocity step rotation toward the contralateral ear remains unchanged. ${ }^{56}$ The VOR time constants are also decreased during the acute phase in both directions. ${ }^{57}$

In vestibular neuritis, direct visualization of the affected vestibular nerve has been reported with gadolinium-enhanced 3-Tesla magnetic resonance imaging (3T MRI). ${ }^{58}$ However, imaging the affected nerve is of more academic interest than of practical utility in vestibular neuritis. In vestibular neuritis, neuroimaging is mostly indicated when a central cause is suspected.

\section{Diagnosis}

Because no confirmatory diagnostic tests are available, vestibular neuritis is primarily a diagnosis of exclusion. Diagnosis of vestibular neuritis is mostly based on a constellation of bedside and laboratory findings (-Table 1). Even though the detailed findings may differ according to the 
Table 1 Clinical features of vestibular neuritis

\begin{tabular}{|l|}
\hline - Subacute or acute onset of spontaneous vertigo with nausea/vomiting \\
\hline - Oscillopsia: Spinning of surroundings in the direction of nystagmus quick phase \\
\hline - Horizontal-torsional spontaneous nystagmus beating toward the unaffected side \\
\hline - Impaired function of the semicircular canals as revealed by head impulse tests or caloric testing \\
\hline - Ipsiversive ocular tilt reaction (head tilt, skew deviation, and ocular torsion) and ipsiversive tilt of the subjective \\
visual vertical/horizontal \\
\hline - Decreased or absent responses of vestibular-evoked myogenic potentials during stimulation of the affected ear \\
\hline - Falling tendency toward the lesion side \\
\hline
\end{tabular}

vestibular divisions affected, the key symptoms and signs of vestibular neuritis generally include acute onset of isolated sustained vertigo with nausea/vomiting, unidirectional horizontal-torsional nystagmus beating away from the lesion side, impaired semicircular function documented by head impulse or caloric tests, ipsiversive OTR and SVV tilt, decreased or abolished VEMP responses during stimulation of the affected ear, and unsteadiness with a falling tendency to the lesion side.

The recent development of the head impulse test and VEMPs has enabled us to evaluate the function all three semicircular canals, utricle, and saccule, and to securely define the subtypes of vestibular neuritis (-Table 2 ).

\section{Superior Vestibular Neuritis}

Superior vestibular neuritis is the most common type. ${ }^{12}$ The spontaneous nystagmus is mostly contraversive horizontaltorsional and upbeating ( $\mathbf{- F i g . ~ 2 A ) . ~}{ }^{12}$ Indeed, three-dimensional recording of eye movements in vestibular neuritis showed that the rotational axes of spontaneous nystagmus clustered along the axis of $\mathrm{HC}$ or between the axes of $\mathrm{HC}$ and AC (-Fig. 2B). ${ }^{12}$ Patients also show a positive head impulse test for the involved AC and HC. Laboratory findings include ipsiversive ocular torsion and tilt of the SVV, ipsilesional caloric paresis, and abnormal ocular VEMP with preservation of hearing and cervical VEMP (-Table 2). ${ }^{1,28,59}$ A head impulse test may be quantified using video-based equipment. $^{41}$

\section{Inferior Vestibular Neuritis}

Vestibular neuritis rarely involves the inferior division only. ${ }^{13,60-62}$ Diagnosis of inferior vestibular neuritis is challenging because the usual signs of vestibular neuritis are absent in this disorder. ${ }^{18}$ As a result, isolated inferior vestibular neuritis may erroneously be ascribed to a central pathology if there is no scrutinized evaluation for the inferior vestibular function. ${ }^{8-10,13,61}$ The spontaneous nystagmus is contraversive torsional and downbeat ( $\mathbf{- F i g . ~ 3 A )})^{18}$ The rotation axis of the spontaneous nystagmus is best aligned with that of the involved PC ( $\mathbf{- F i g . ~ 3 B}) .{ }^{18}$ Other findings include a positive head impulse test only for the affected PC and an abnormal cervical VEMP in response to ACS in the presence of normally functioning $\mathrm{HC}$ and AC, as determined by a normal head impulse test and caloric test (- Table 2). ${ }^{62}$ Ocular torsion, SVV, and ocular VEMP are mostly within the normal range (-Fig. $\mathbf{3 C}-\mathbf{G}$ ). Some patients may have tinnitus and hearing loss in the involved side. ${ }^{13,18}$

\section{Total Vestibular Neuritis}

The spontaneous nystagmus is mostly torsional-horizontal beating away from the affected ear. Otherwise, the patients with total vestibular neuritis would show all the

Table 2 Comparison of the findings among the subtypes of vestibular neuritis

\begin{tabular}{|l|l|l|l|}
\hline & Superior & Inferior & Total \\
\hline SN & H(C)-T(C)-U & T(C)-D & $H(C)-T(C)$ \\
\hline HIT-AC & Impaired & Normal & Impaired \\
\hline HIT-HC & Impaired & Normal & Impaired \\
\hline HIT-PC & Normal & Impaired & Impaired \\
\hline Caloric test & Abnormal & Normal & Abnormal \\
\hline OTR & Ipsiversive & Normal & Ipsiversive \\
\hline SVV & Ipsiversive & Normal & Ipsiversive \\
\hline oVEMP & Abnormal & Normal & Abnormal \\
\hline CVEMP & Normal & Abnormal & Abnormal \\
\hline
\end{tabular}

Abbreviations: AC, anterior semicircular canal; C, contraversive (quick phase); cVEMP, cervical vestibular-evoked myogenic potential; D, downbeat; $\mathrm{H}$, horizontal; HC, horizontal semicircular canal; HIT, head impulse test; OTR, ocular tilt reaction; oVEMP, ocular vestibular-evoked myogenic potential; PC, posterior semicircular canal; SN, spontaneous nystagmus; SVV, subjective visual vertical; T, torsional; U, upbeat. 
A

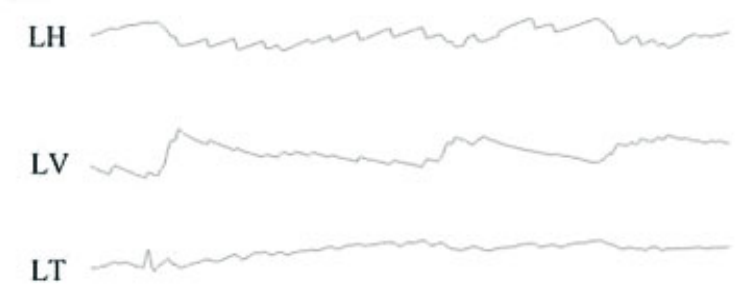

B

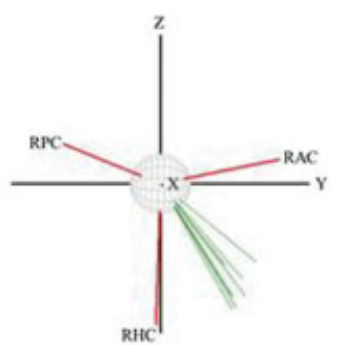

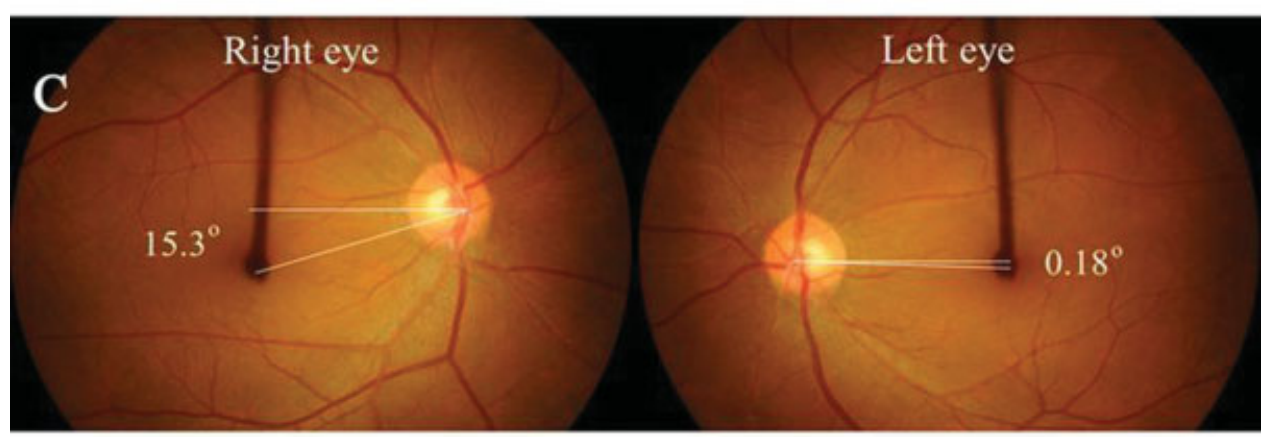

D

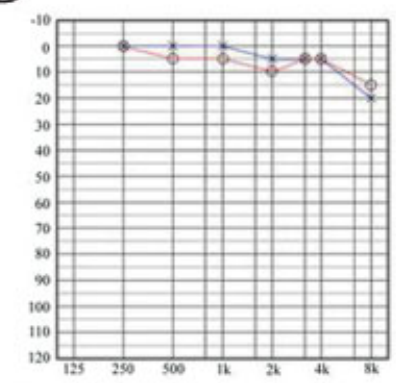

F

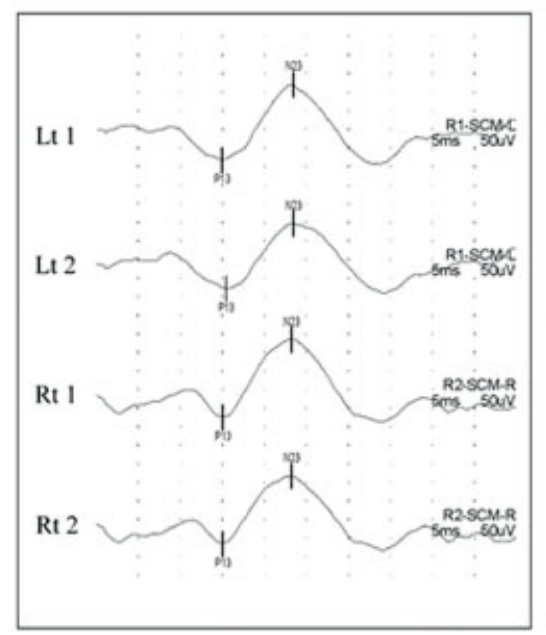

$\mathrm{E}$
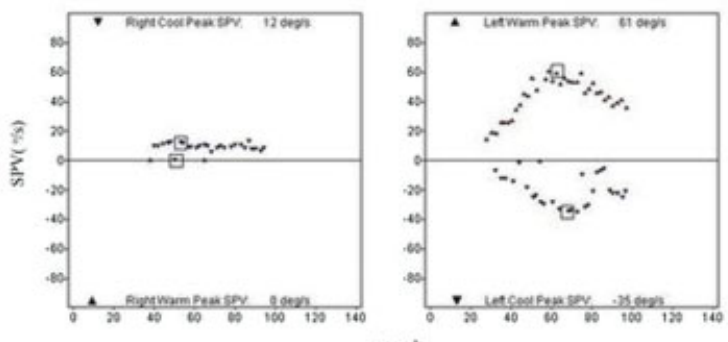

seconds

Fig. 2 Clinical features of superior vestibular neuritis. (A) A patient with right vestibular neuritis involving the superior division shows left beat, upbeat, and counterclockwise (from the patient's perspective) torsional nystagmus. (B) The rotational axes of the spontaneous nystagmus cluster between those of anterior and horizontal semicircular canal. (C) Rightward ocular torsion is noted on fundus photos (normal range: 0-12.6 degrees; negative values indicate intorsion.). (D-G) The patient also shows right caloric paresis (E) and decreased amplitude of ocular vestibularevoked myogenic potential (VEMP) during right ear stimulation with air-conducted sounds (ACS) in the presence of normal hearing (D) and cervical VEMP to ACS (F). In (A), upward deflection indicates rightward, upward, and clockwise torsional eye motion. In (B), the rotational axis of each canal was calculated from the data of Della Santina et al. ${ }^{93}$ (LH, horizontal position of the left eye; LV, vertical position of the left eye; LT, torsional position of the left eye; RHC, right horizontal semicircular canal; RAC, right anterior semicircular canal; RPC, right posterior semicircular canal semicircular canal). 
A

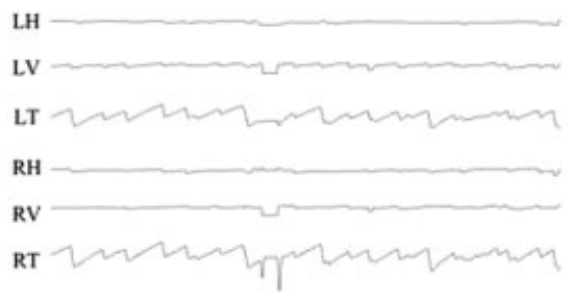

B

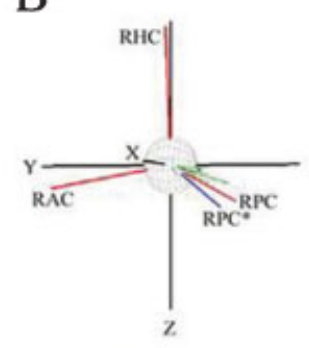

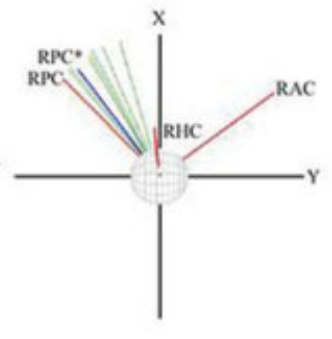

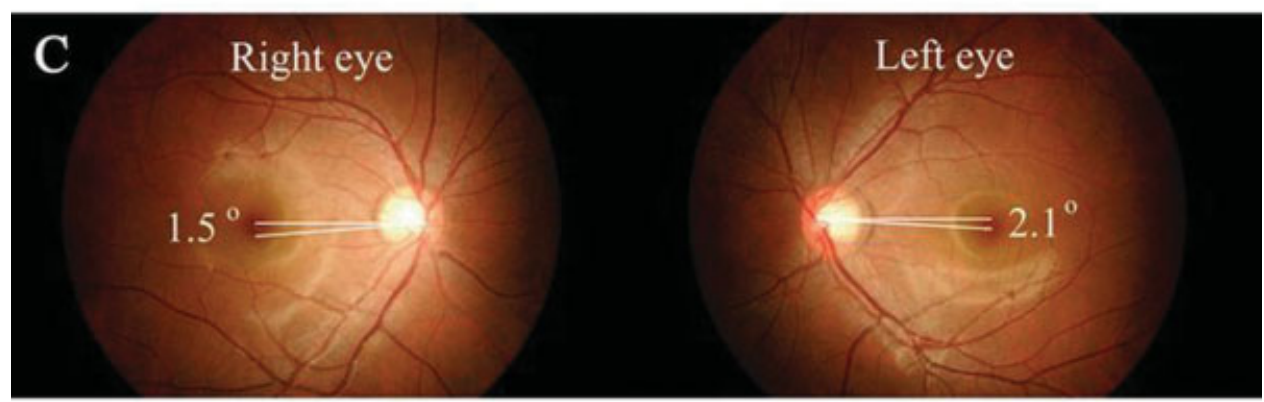

D

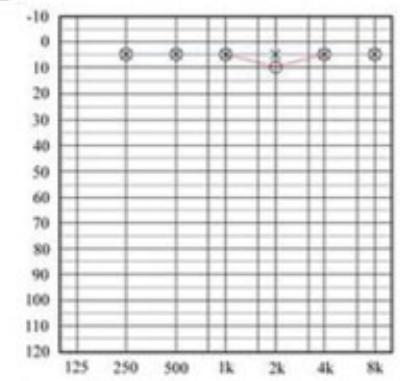

$\mathrm{E}$

\section{F}
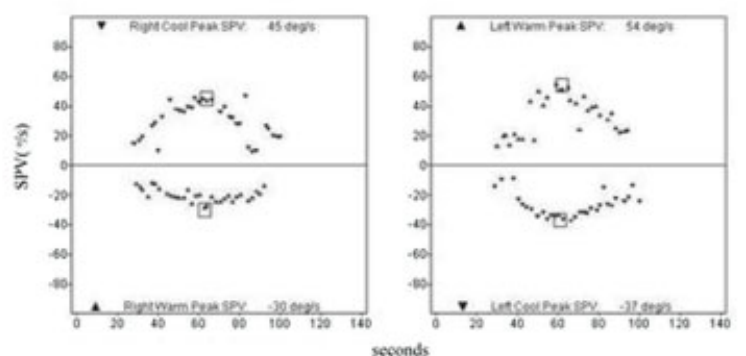

G
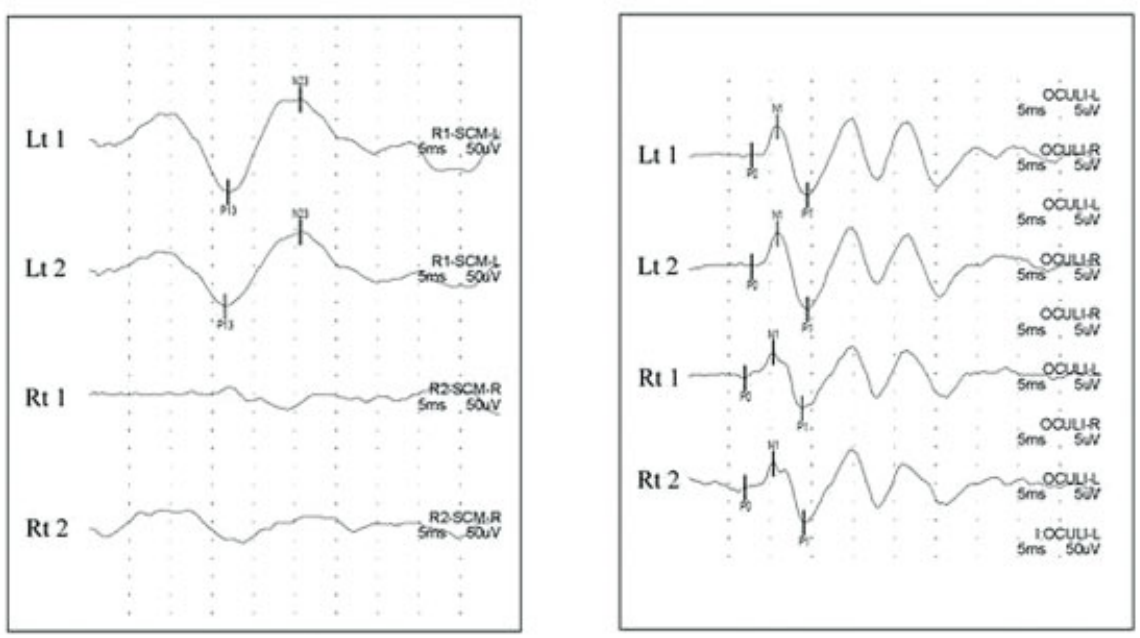

Fig. 3 Clinical features of inferior vestibular neuritis. (A) A patient with right inferior vestibular neuritis shows counterclockwise (from the patient's perspective) torsional and downbeat nystagmus. (B) The rotational axes of the spontaneous nystagmus cluster around that of posterior semicircular canal. (C-G) The patient shows no wave formation of right cervical vestibular-evoked myogenic potential (VEMP) in response to airconducted sounds (F), while the findings of fundus photos (C), audiometry (D), bithermal caloric tests (E), and ocular VEMP induced by ACS (G) are normal. In (A), upward deflection indicates rightward, upward, and clockwise torsional eye motion. In (B), the axes in red were calculated from the data of Della Santina et al ${ }^{93}$; the axis in blue was constructed from the data of Blanks et al. ${ }^{94}$ (LH, horizontal position of the left eye; LV, vertical position of the left eye; LT, torsional position of the left eye; RH, horizontal position of the right eye; RV, vertical position of the right eye; RT, torsional position of the right eye; RHC. right horizontal semicircular canal; RAC, right anterior semicircular canal; RPC, right posterior semicircular canal semicircular canal). 
abnormalities observed in superior and inferior vestibular neuritis (-Table 2 ).

\section{Course}

Severe vertigo and static vestibular imbalance markedly improve over a few days in most patients with a gradual resolution over the following weeks. ${ }^{1,28}$ Improvement of the initial symptoms occurs by virtue of central compensation for the vestibular tone imbalance rather than by recovery of the function in the affected ear. ${ }^{63}$ One of the central compensation signs is the reduction of spontaneous nystagmus, which usually takes 3 weeks to subside. ${ }^{64}$ Neural recordings in animals recovering from unilateral vestibular deafferentation show that central compensation depends on restoration of normal spontaneous activity in the ipsilesional vestibular nucleus, thereby rebalancing the activity between the left and right vestibular nuclei. ${ }^{7,65}$ Later, when the vestibular function is restored in the damaged ear, mild spontaneous nystagmus may beat in the opposite direction (recovery nystagmus). ${ }^{66}$ Although the static symptoms invariably resolve, albeit often not totally, the dynamic symptoms may last longer or persist. ${ }^{28}$ In a previous study, the static vestibular imbalances (spontaneous nystagmus, ipsilesional SVV tilt, and ocular torsion) had mostly resolved by 3 months after symptoms onset, whereas the signs of dynamic vestibular imbalances (head impulse test, head-shaking nystagmus, vibration-induced nystagmus, and caloric test) can still be observed in more than $30 \%$ of the patients at 1 year from symptom onset. ${ }^{28}$ Tests of the VOR function using a rotary chair yielded similar results. When tested 3 to 5 days after the onset of vestibular neuritis, ${ }^{67-69}$ the responses to low acceleration whole-body rotation in the lesion side was decreased to $50 \%$, and in the healthy side to $75 \%$ of normal controls. Of note, the VOR responses to rotations in the healthy side were also decreased, which may be ascribed to central compensation to improve the response asymmetry. The VOR responses to the rotation in the affected side increase with time. This improvement may result from either central compensation or periphery recovery, observed as improvement in caloric responses by an average of $30 \% .{ }^{68}$ When tested 3 months later, the majority of patients showed symmetrical responses with an increase of the responses during rotation toward the involved side. This pattern is similar, but less pronounced in the pitch plane. ${ }^{69}$ In view of more rapid resolution of the static vestibular imbalances after vestibular neuritis, ${ }^{28}$ evaluation of the dynamic vestibular imbalance may provide more useful information for underlying vestibulopathy, especially in the compensated phase. In a few patients with limited restoration of the labyrinthine function, oscillopsia may persist during rapid head movements. ${ }^{70}$ This is caused by a persisting deficit of the VOR in the higher frequency range, which cannot be compensated for centrally. The persistent loss of balance that some patients experience after acute vestibular neuritis may be due to inadequate central compensation or due to incomplete peripheral recovery. Vestibular rehabilitation has a role in treating both. $^{70}$

Vestibular neuritis is known to recur only in 2 to $11 \%$ of patients. ${ }^{71,72}$ In 10 to $15 \%$ of patients with vestibular neuritis, a typical benign paroxysmal positional vertigo develops in the affected ear within a few weeks, ${ }^{73}$ which suggests that the otoconia may be loosened due to inflammation of the labyrinth. The second most important complication is phobic postural vertigo, which entails persistent dizziness and unsteadiness associated with fear of falling without any real falls or vestibular dysfunction that can explain the symptoms. ${ }^{74}$

\section{Differential Diagnosis}

Acute unilateral peripheral vestibulopathy may also be caused by vascular compromise of the peripheral vestibular labyrinth. ${ }^{19,75}$ Diagnosis of isolated labyrinthine infarction remains a diagnostic challenge because current imaging techniques cannot detect it. ${ }^{20}$ However, isolated labyrinthine infarction is exceedingly rare, and usually accompanies cochlear damage and resultant hearing loss. ${ }^{75,76}$ Rarely, isolated labyrinthine infarction may progress to involve the brainstem or cerebellar territory supplied by the anterior inferior cerebellar artery (AICA). ${ }^{76}$ Vestibular pseudoneuritis has also been described in infarctions involving the vestibular nucleus ${ }^{77}$ or inferior cerebellum..$^{21,78,79}$ Occasionally, serial evaluation is necessary because even the diffusion-weighted MRI may fail to detect a small infarction involving the brainstem or cerebellum during the acute phase. ${ }^{20,76,80}$ Plaques of multiple sclerosis or lacunar infarctions involving the root entry zone of the eighth nerve may mimic vestibular neuritis. ${ }^{81}$ From a clinical point of view, the first question to be answered in patients with acute vertigo and nystagmus is whether the symptoms are caused by vestibular neuritis or by central vestibular pseudoneuritis. ${ }^{20}$ It is not always easy to differentiate isolated vascular vertigo from acute peripheral vestibulopathy at the bedside. However, a rather simple neuro-otological examination including a normal horizontal head impulse test, direction-changing nystagmus, and skew deviation (HINTS) can reliably detect central vertigo with a high sensitivity and specificity. ${ }^{82}$ Even these bedside tests are more sensitive for stroke than early MRIs, while maintaining a high specificity. ${ }^{82-86}$ Indeed, initial diffusion-weighted MRI may be false-negative in 12 to $20 \%$ of the stroke patients within the first 48 hours. ${ }^{82,83}$ Because a mild degree of skew deviation is hard to detect in the presence of spontaneous nystagmus, and gaze-evoked nystagmus may be absent in cerebellar stroke, a bedside head impulse test appears to be the best tool for differentiating isolated vascular vertigo from acute vestibular neuritis. ${ }^{82}$ However, because a bedside head impulse test may be negative in patients with covert corrective saccades and may be inconclusive in patients with nystagmus, recording of the head impulse test using a video-based equipment may be helpful in patients with equivocal results. ${ }^{41}$ Of course, a positive head impulse test does not necessarily eliminate the possibility of central lesions. ${ }^{79,85-87}$ Because recurrence is rare in vestibular neuritis, an alternative diagnosis should be considered whenever patients report more than one episode. ${ }^{88}$

\section{Treatment}

Treatments of vestibular neuritis generally include supportive care during the acute phase, steroids, and vestibular rehabilitation. 
Symptomatic care with vestibular suppressants should be applied only during the first several days when the patients suffer from severe nausea/vomiting and vertigo because these medications may delay the central compensation. ${ }^{23}$

Based on the shared theory of viral etiology in vestibular neuritis and Bell's palsy, antiviral agents and steroids have been tried. ${ }^{89}$ However, the efficacy of corticosteroids is controversial. A recent Cochrane review concluded that there is currently insufficient evidence to support the use of corticosteroids in patients with idiopathic acute vestibular dysfunction. ${ }^{90}$ This review found four trials (total of 149 participants) that compared oral corticosteroids against placebo. Although there was a significant effect of corticosteroids on complete caloric recovery at 1 month, the review demonstrated no significant effect of corticosteroids on complete caloric recovery at 12 months, the extent of caloric recovery after 1 or 12 months, symptomatic recovery from vertigo at 24 hours, or the Dizziness Handicap Inventory score at 1, 3, 6, and 12 months. Further studies are also required regarding effects on subjective improvements and quality of life. ${ }^{91}$ The administration of valacyclovir alone or its administration in combination with glucocorticoids revealed no effect either. ${ }^{89}$

A prospective study demonstrated that specific vestibular exercises significantly improve vestibulospinal compensation in patients with acute vestibular neuritis. ${ }^{64}$ There is moderate evidence that vestibular rehabilitation therapy is effective during the acute period of vestibular neuritis. ${ }^{70}$ Equilibrium training significantly lessens the time required for vestibulospinal compensation and postural regulation to develop. Voluntary eye movements and fixations are exercised to improve impaired visual fixation. Furthermore, active head movements as well as balance tasks, goal-directed movements, and walking should be encouraged to realign the vestibular reflex, and to improve vestibulospinal postural regulation and goal-directed motor function. ${ }^{70}$ Patients should exercise at least for 30 minutes three times a day. A recent report showed that the visual compensation device such as Nintendo Wii Balance Board (Nintendo, Inc., Redwood, WA) also aids in vestibular compensation, even with steroids. ${ }^{92}$

\section{Conclusion}

Careful history taking and a focused neurologic examination are usually enough for diagnosis of vestibular neuritis. With the aids of a head impulse test and cervical and ocular VEMPs, each subtype of vestibular neuritis can be securly diagnosed as superior, inferior, or total vestibular neuritis. Even though very rare, inferior vestibular neuritis should be considered in patients with acute spontaneous vertigo and torsional downbeat nystagmus. Imaging should be considered whenever there is any finding inconsistent with vestibular neuritis because it is a diagnosis of exclusion. Management during the acute phase is primarily supportive while long-term treatment should be designed to improve vestibular compensation.

\section{Acknowledgments}

This study was supported by a grant (0420-2009-0000) for R\&D projects from the Small and Medium Business Administration.

\section{References}

1 Baloh RW, Kerber KA. Clinical Neurophysiology of the Vestibular System. 4th ed. New York: Oxford University Press; 2011

2 Dix MR, Hallpike CS. The pathology, symptomatology and diagnosis of certain common disorders of the vestibular system. Ann Otol Rhinol Laryngol 1952;61(4):987-1016

3 Kroenke K, Hoffman RM, Einstadter D. How common are various causes of dizziness? A critical review. South Med J 2000;93(2): 160-167, quiz 168

4 Brandt T, Dieterich M, Strupp M. Vertigo and dizziness: common complaints. London: Springer; 2005

5 Sekitani T, Imate Y, Noguchi T, Inokuma T. Vestibular neuronitis: epidemiological survey by questionnaire in Japan. Acta Otolaryngol Suppl 1993;503:9-12

6 Strupp M, Brandt T. Vestibular neuritis. Semin Neurol 2009;29 (5):509-519

7 Halmagyi GM, Weber KP, Curthoys IS. Vestibular function after acute vestibular neuritis. Restor Neurol Neurosci 2010;28(1):37-46

8 Halmagyi GM, Curthoys IS. A clinical sign of canal paresis. Arch Neurol 1988;45(7):737-739

9 Halmagyi GM, Aw ST, Cremer PD, Curthoys IS, Todd MJ. Impulsive testing of individual semicircular canal function. Ann N Y Acad Sci 2001;942:192-200

10 Halmagyi GM, Colebatch JG. Vestibular evoked myogenic potentials in the sternomastoid muscle are not of lateral canal origin. Acta Otolaryngol Suppl 1995;520(Pt 1):1-3

11 Rosengren SM, McAngus Todd NP, Colebatch JG. Vestibular-evoked extraocular potentials produced by stimulation with bone-conducted sound. Clin Neurophysiol 2005;116(8):1938-1948

12 Fetter M, Dichgans J. Vestibular neuritis spares the inferior division of the vestibular nerve. Brain 1996;119(Pt 3):755-763

13 Aw ST, Fetter M, Cremer PD, Karlberg M, Halmagyi GM. Individual semicircular canal function in superior and inferior vestibular neuritis. Neurology 2001;57(5):768-774

14 Shin BS, Oh SY, Kim JS, et al. Cervical and ocular vestibular-evoked myogenic potentials in acute vestibular neuritis. Clin Neurophysiol 2012;123(2):369-375

15 Lin CM, Young YH. Identifying the affected branches of vestibular nerve in vestibular neuritis. Acta Otolaryngol 2011;131(9): 921-928

16 Bartolomeo M, Biboulet R, Pierre G, Mondain M, Uziel A, Venail F. Value of the video head impulse test in assessing vestibular deficits following vestibular neuritis. Eur Arch Otorhinolaryngol 2013; Epub ahead of print

17 Walther LE, Blödow A. Ocular vestibular evoked myogenic potential to air conducted sound stimulation and video head impulse test in acute vestibular neuritis. Otol Neurotol 2013;34(6):1084-1089

18 Kim JS, Kim HJ. Inferior vestibular neuritis. J Neurol 2012;259 (8):1553-1560

$19 \mathrm{Kim}$ JS, Lee $\mathrm{H}$. Inner ear dysfunction due to vertebrobasilar ischemic stroke. Semin Neurol 2009;29(5):534-540

20 Choi KD, Lee H, Kim JS. Vertigo in brainstem and cerebellar strokes. Curr Opin Neurol 2013;26(1):90-95

21 Lee H, Sohn SI, Cho YW, et al. Cerebellar infarction presenting isolated vertigo: frequency and vascular topographical patterns. Neurology 2006;67(7):1178-1183

22 Hotson JR, Baloh RW. Acute vestibular syndrome. N Engl J Med 1998;339(10):680-685

23 Baloh RW. Clinical practice. Vestibular neuritis. N Engl J Med 2003;348(11):1027-1032 
24 Lee H, Kim BK, Park HJ, Koo JW, Kim JS. Prodromal dizziness in vestibular neuritis: frequency and clinical implication. J Neurol Neurosurg Psychiatry 2009;80(3):355-356

25 Silvoniemi P. Vestibular neuronitis. An otoneurological evaluation. Acta Otolaryngol Suppl 1988;453:1-72

26 Suzuki JI, Cohen B. Head, eye, body and limb movements from semicircular canal nerves. Exp Neurol 1964;10:393-405

27 Leigh RJ, Zee DS. The neurology of eye movements. 4th ed. New York, NY: Oxford University Press; 2006

28 Choi KD, Oh SY, Kim HJ, Koo JW, Cho BM, Kim JS. Recovery of vestibular imbalances after vestibular neuritis. Laryngoscope 2007;117(7):1307-1312

29 Choi KD, Kim JS, Kim HJ, et al. Hyperventilation-induced nystagmus in peripheral vestibulopathy and cerebellopontine angle tumor. Neurology 2007;69(10):1050-1059

30 Brandt T, Dieterich M. Vestibular falls. J Vestib Res 1993;3(1):3-14

31 Davis LE. Viruses and vestibular neuritis: review of human and animal studies. Acta Otolaryngol Suppl 1993;503:70-73

32 Arbusow V, Schulz P, Strupp M, et al. Distribution of herpes simplex virus type 1 in human geniculate and vestibular ganglia: implications for vestibular neuritis. Ann Neurol 1999;46(3):416-419

33 Arbusow V, Derfuss T, Held K, et al. Latency of herpes simplex virus type- 1 in human geniculate and vestibular ganglia is associated with infiltration of CD8 + T cells. J Med Virol 2010;82(11):1917-1920

34 Esaki S, Goshima F, Kimura H, et al. Auditory and vestibular defects induced by experimental labyrinthitis following herpes simplex virus in mice. Acta Otolaryngol 2011;131(7):684-691

35 Gianoli G, Goebel J, Mowry S, Poomipannit P. Anatomic differences in the lateral vestibular nerve channels and their implications in vestibular neuritis. Otol Neurotol 2005;26(3):489-494

36 Bergström B. Morphology of the vestibular nerve. II. The number of myelinated vestibular nerve fibers in man at various ages. Acta Otolaryngol 1973;76(2):173-179

37 Choi KD, Oh SY, Park SH, Kim JH, Koo JW, Kim JS. Head-shaking nystagmus in lateral medullary infarction: patterns and possible mechanisms. Neurology 2007;68(17):1337-1344

38 Jorns-Häderli M, Straumann D, Palla A. Accuracy of the bedside head impulse test in detecting vestibular hypofunction. J Neurol Neurosurg Psychiatry 2007;78(10):1113-1118

39 Perez N, Rama-Lopez J. Head-impulse and caloric tests in patients with dizziness. Otol Neurotol 2003;24(6):913-917

40 Weber KP, Aw ST, Todd MJ, McGarvie LA, Curthoys IS, Halmagyi GM. Head impulse test in unilateral vestibular loss: vestibuloocular reflex and catch-up saccades. Neurology 2008;70(6): 454-463

41 MacDougall HG, Weber KP, McGarvie LA, Halmagyi GM, Curthoys IS. The video head impulse test: diagnostic accuracy in peripheral vestibulopathy. Neurology 2009;73(14):1134-1141

$42 \mathrm{Kim} \mathrm{HA}$, Hong JH, Lee $\mathrm{H}$, et al. Otolith dysfunction in vestibular neuritis: recovery pattern and a predictor of symptom recovery. Neurology 2008;70(6):449-453

43 Curthoys IS, Dai MJ, Halmagyi GM. Human ocular torsional position before and after unilateral vestibular neurectomy. Exp Brain Res 1991;85(1):218-225

44 Tabak S, Collewijn H, Boumans LJ. Deviation of the subjective vertical in long-standing unilateral vestibular loss. Acta Otolaryngol 1997;117(1):1-6

45 Vibert D, Häusler R. Long-term evolution of subjective visual vertical after vestibular neurectomy and labyrinthectomy. Acta Otolaryngol 2000;120(5):620-622

46 Zwergal A, Rettinger N, Frenzel C, Dieterich M, Brandt T, Strupp M. A bucket of static vestibular function. Neurology 2009;72(19): 1689-1692

47 Kushiro K, Zakir M, Ogawa Y, Sato H, Uchino Y. Saccular and utricular inputs to sternocleidomastoid motoneurons of decerebrate cats. Exp Brain Res 1999;126(3):410-416

48 Govender S, Colebatch JG. Ocular vestibular evoked myogenic potential (oVEMP) responses in acute vestibular neuritis. Clin
Neurophysiol 2012;123(5):1054-1055, author reply 1055-1056, discussion 1056-1057

49 Isu N, Graf W, Sato H, et al. Sacculo-ocular reflex connectivity in cats. Exp Brain Res 2000;131(3):262-268

50 Curthoys IS. The interpretation of clinical tests of peripheral vestibular function. Laryngoscope 2012;122(6):1342-1352

51 Brantberg K, Tribukait A, Fransson PA. Vestibular evoked myogenic potentials in response to skull taps for patients with vestibular neuritis. J Vestib Res 2003;13(2-3):121-130

52 Halmagyi GM, Carey JP. Vestibular evoked myogenic potentials we live in interesting times. Clin Neurophysiol 2010;121(5): 631-633

53 Rosengren SM, Kingma H. New perspectives on vestibular evoked myogenic potentials. Curr Opin Neurol 2013;26(1):74-80

54 Ushio M, Iwasaki S, Murofushi T, et al. The diagnostic value of vestibular-evoked myogenic potential in patients with vestibular schwannoma. Clin Neurophysiol 2009;120(6):1149-1153

55 Curthoys IS, Iwasaki S, Chihara Y, Ushio M, McGarvie LA, Burgess AM. The ocular vestibular-evoked myogenic potential to air-conducted sound; probable superior vestibular nerve origin. Clin Neurophysiol 2011;122(3):611-616

56 Baloh RW, Jacobson KM, Beykirch K, Honrubia V. Horizontal vestibulo-ocular reflex after acute peripheral lesions. Acta Otolaryngol Suppl 1989;468:323-327

57 Brantberg K, Magnusson M. The dynamics of the vestibulo-ocular reflex in patients with vestibular neuritis. Am J Otolaryngol 1990;11(5):345-351

58 Karlberg M, Annertz M, Magnusson M. Acute vestibular neuritis visualized by 3-T magnetic resonance imaging with high-dose gadolinium. Arch Otolaryngol Head Neck Surg 2004;130(2):229232

59 Halmagyi GM, Weber KP, Curthoys IS. Vestibular function after acute vestibular neuritis. Restor Neurol Neurosci 2010;28(1):3746

60 Monstad P, Økstad S, Mygland A. Inferior vestibular neuritis: 3 cases with clinical features of acute vestibular neuritis, normal calorics but indications of saccular failure. BMC Neurol 2006;6:45

61 Halmagyi GM, Aw ST, Karlberg M, Curthoys IS, Todd MJ. Inferior vestibular neuritis. Ann N Y Acad Sci 2002;956:306-313

62 Kim JS, Kim HJ. Inferior vestibular neuritis. J Neurol 2012;259 (8):1553-1560

63 Gliddon CM, Darlington CL, Smith PF. GABAergic systems in the vestibular nucleus and their contribution to vestibular compensation. Prog Neurobiol 2005;75(1):53-81

64 Strupp M, Arbusow V, Maag KP, Gall C, Brandt T. Vestibular exercises improve central vestibulospinal compensation after vestibular neuritis. Neurology 1998;51(3):838-844

65 Lacour M, Tighilet B. Plastic events in the vestibular nuclei during vestibular compensation: the brain orchestration of a "deafferentation" code. Restor Neurol Neurosci 2010;28(1):19-35

66 Jacobson GP, Pearlstein R, Henderson J, Calder JH, Rock J. Recovery nystagmus revisited. J Am Acad Audiol 1998;9(4):263-271

67 Allum JH, Ledin T. Recovery of vestibulo-ocular reflex-function in subjects with an acute unilateral peripheral vestibular deficit. J Vestib Res 1999;9(2):135-144

68 Allum JH, Adkin AL. Improvements in trunk sway observed for stance and gait tasks during recovery from an acute unilateral peripheral vestibular deficit. Audiol Neurootol 2003;8(5): $\quad 286-$ 302

69 Allum JH, Yamane M, Pfaltz CR. Long-term modifications of vertical and horizontal vestibulo-ocular reflex dynamics in man. I. After acute unilateral peripheral vestibular paralysis. Acta Otolaryngol 1988;105(3-4):328-337

70 Herdman SJ. Vestibular rehabilitation. Curr Opin Neurol 2013;26 (1):96-101

71 Huppert D, Strupp M, Theil D, Glaser M, Brandt T. Low recurrence rate of vestibular neuritis: a long-term follow-up. Neurology 2006;67(10):1870-1871 
72 Kim YH, Kim KS, Kim KJ, Choi H, Choi JS, Hwang IK. Recurrence of vertigo in patients with vestibular neuritis. Acta Otolaryngol 2011;131(11):1172-1177

73 Mandalà M, Santoro GP, Awrey J, Nuti D. Vestibular neuritis: recurrence and incidence of secondary benign paroxysmal positional vertigo. Acta Otolaryngol 2010;130(5):565-567

74 Brandt T. Phobic postural vertigo. Neurology 1996;46(6): 1515-1519

75 Lee H, Kim JS, Chung EJ, et al. Infarction in the territory of anterior inferior cerebellar artery: spectrum of audiovestibular loss. Stroke 2009;40(12):3745-3751

$76 \mathrm{Kim} \mathrm{JS}$, Cho KH, Lee H. Isolated labyrinthine infarction as a harbinger of anterior inferior cerebellar artery territory infarction with normal diffusion-weighted brain MRI. J Neurol Sci 2009;278 (1-2):82-84

$77 \mathrm{Kim} \mathrm{HA}$, Lee $\mathrm{H}$. Isolated vestibular nucleus infarction mimicking acute peripheral vestibulopathy. Stroke 2010;41(7):1558-1560

78 Lee $\mathrm{H}$, Cho YW. A case of isolated nodulus infarction presenting as a vestibular neuritis. J Neurol Sci 2004;221(1-2):117-119

79 Park HK, Kim JS, Strupp M, Zee DS. Isolated floccular infarction: impaired vestibular responses to horizontal head impulse. J Neurol 2013;260(6):1576-1582

80 Kim DR, Lee HJ, Kim HJ, Hong SK. Dynamic changes in the inner ear function and vestibular neural pathway related to the progression of labyrinthine infarction in patient with an anterior inferior cerebellar artery infarction. Otol Neurotol 2011;32(9):1596-1599

81 Thömke F, Hopf HC. Pontine lesions mimicking acute peripheral vestibulopathy. J Neurol Neurosurg Psychiatry 1999;66(3):340-349

82 Kattah JC, Talkad AV, Wang DZ, Hsieh YH, Newman-Toker DE. HINTS to diagnose stroke in the acute vestibular syndrome: threestep bedside oculomotor examination more sensitive than early MRI diffusion-weighted imaging. Stroke 2009;40(11):3504-3510

83 Tarnutzer AA, Berkowitz AL, Robinson KA, Hsieh YH, NewmanToker DE. Does my dizzy patient have a stroke? A systematic review of bedside diagnosis in acute vestibular syndrome. CMAJ 2011;183(9):E571-E592
84 Chen L, Lee W, Chambers BR, Dewey HM. Diagnostic accuracy of acute vestibular syndrome at the bedside in a stroke unit. J Neurol 2011;258(5):855-861

85 Newman-Toker DE, Kattah JC, Alvernia JE, Wang DZ. Normal head impulse test differentiates acute cerebellar strokes from vestibular neuritis. Neurology 2008;70(24 Pt 2):2378-2385

86 Cnyrim CD, Newman-Toker D, Karch C, Brandt T, Strupp M. Bedside differentiation of vestibular neuritis from central "vestibular pseudoneuritis". J Neurol Neurosurg Psychiatry 2008;79(4): 458-460

87 Kremmyda O, Kirchner H, Glasauer S, Brandt T, Jahn K, Strupp M. False-positive head-impulse test in cerebellar ataxia. Front Neurol 2012;3:162

88 Kerber KA. Vertigo and dizziness in the emergency department. Emerg Med Clin North Am 2009;27(1):39-50, viii

89 Strupp M, Zingler VC, Arbusow V, et al. Methylprednisolone, valacyclovir, or the combination for vestibular neuritis. N Engl Med 2004;351(4):354-361

90 Fishman JM, Burgess C, Waddell A. Corticosteroids for the treatment of idiopathic acute vestibular dysfunction (vestibular neuritis). Cochrane Database Syst Rev 2011;11(5):CD008607

91 Wegner I, van Benthem PP, Aarts MC, Bruintjes TD, Grolman W, van der Heijden GJ. Insufficient evidence for the effect of corticosteroid treatment on recovery of vestibular neuritis. Otolaryngol Head Neck Surg 2012;147(5):826-831

92 Sparrer I, Duong Dinh TA, Ilgner J, Westhofen M. Vestibular rehabilitation using the Nintendo ${ }^{\circledR}$ Wii Balance Board - a userfriendly alternative for central nervous compensation. Acta Otolaryngol 2013;133(3):239-245

93 Della Santina CC, Potyagaylo V, Migliaccio AA, Minor LB, Carey JP. Orientation of human semicircular canals measured by threedimensional multiplanar CT reconstruction. J Assoc Res Otolaryngol 2005;6(3):191-206

94 Blanks RH, Curthoys IS, Markham CH. Planar relationships of the semicircular canals in man. Acta Otolaryngol 1975;80(3-4): 185-196 